\title{
Research Effects of Person-Environment Fit of Gender- Role Orientation on Burnout, Engagement and Hair Steroids as Stress Biomarkers Among Women
}

\author{
Eva Wacker ( $\nabla$ wacker_eva@yahoo.com ) \\ Charite Universitatsmedizin Berlin Campus Charite Mitte: Charite Universitatsmedizin Berlin \\ Julia Schorlemmer \\ FOM Hochschule - Standort Berlin \\ Axel Fischer \\ Charité Universitätsmedizin Berlin Campus Charite Mitte: Charite Universitatsmedizin Berlin
}

\section{Research}

Keywords: Person-Environment fit, Gender-Role Orientation, Burnout, Engagement, Hair Steroids

Posted Date: February 1st, 2021

DOI: https://doi.org/10.21203/rs.3.rs-162495/v1

License: (c) (1) This work is licensed under a Creative Commons Attribution 4.0 International License. Read Full License

Version of Record: A version of this preprint was published at Journal of Occupational Medicine and Toxicology on April 16th, 2021. See the published version at https://doi.org/10.1186/s12995-021-00303-5. 


\section{Abstract \\ Background}

Gender differences usually reveal higher occupational stress and burnout levels for women compared to men, especially in male-dominated working environments. In opposition to group differentiation, more specific genderrelated dimensions feminity and masculinity were used in the study to describe individual and work environment characteristics and analyze their effects.

\section{Methods}

Two Person-Environment fit scores in feminity and masculinity were calculated by subtracting individual from environment values. Both fit scores were proved as predictors in hierarchical linear regression models predicting burnout and work engagement as well as hair steroids cortisol, cortisone, DHEA, testosterone and progesterone detected by Liquid Chromatography-Mass Spectrometry (LC-MS/MS) as stress biomarkers. Age as control variable and workplace characteristics were included in the analysis. Bivariate correlations as well as moderator and mediator analysis were implemented. Data was collected in a German medical services company with 146 employed women age $22-66$ years $(M=40.48, S D=10.38)$, 58 of them provided hair samples for steroid detection.

\section{Results}

After considering age, role clarity, and work organization, Person-Environment fit in feminity still added significant variance explanation $\left(\beta=.23, \Delta R^{2}=.05, p=.003\right)$ for burnout $\left(R^{2}=0.40, p<.001\right)$. Person-Environment fit in feminity also explained poor variance in work engagement $\left(\beta=-.29, R^{2}=.09, p<.001\right)$. Person-Environment fit in masculinity added considerable variance explanation $\left(\beta=.34, \Delta R^{2}=.12, p=0.018\right)$ to cortisol levels $\left(R^{2}=.19, p=.012\right)$ after including quantitative demands to the model.

\section{Conclusions}

Person-Environment fit in feminity might be inspected as a predictor for burnout and work engagement. PersonEnvironment fit in masculinity can be taken into consideration as a predictor for hair cortisol as stress biomarker. Feminity and masculinity can be used as personality traits as well as characteristics of work environment, thus providing a particular gender-role related method of differentiation within gender groups. Also, specific methods could be derived for stress and burnout prevention and promotion of work engagement. Representative population studies with bigger samples and longitudinal surveys are needed to better explore the benefits and limitations of this approach.

\section{Background}

In the last decades different phenomena have emphasized the relevance of gender research in relation to stress and burnout. The growing numbers of burnout and psychological illnesses reveal the importance of the related fundamental research [1]. Additionally, the increasing entry of women into the labor market and the ongoing war for talents in the industrial countries [2] reinforce the need for more appropriate approaches to address these health 
issues by occupational medicine and psychology. To sensitize the public to the issues of sex and gender research the European Research Council hosted a special workshop in November 2020 [3].

Proceeding research shows a tendency for higher stress and burnout levels as well as poorer psychological health scores for women compared to men $[4,5]$. In most studies stress coping strategies and health strains have been compared for female and male groups, also considering the gender congruency of the individuals and their work environment, e.g. female employees with male supervisors or women in male-dominated teams and organizations [4]. These studies were based on individuals' biological sex and gender as a cultural and social role, not differentiating within gender groups, which does not consider diversity among women and among men.

Another research direction provides a more specified view on gender-related characteristics since the 1970s, as feminity and masculinity as personality dimensions are focused on, instead of the very rough differentiation of sex or gender groups. Our study follows this scientific argumentation, also picking up the idea of lacking congruence between the individuals and their work environment as a possible stress factor. Accordingly, individual and work environment feminity and masculinity were used to calculate two fit scores analyzed as predictors for subjective health strain measures, hair steroids as biological stress markers, and work engagement.

\section{Person-Environment Fit}

The construct Person-Environment fit can be generally explained as congruence between the individual and its environment [6]. Theory of Work Adjustment $[7,8]$ describes it with the term correspondence, other theories refer to it as fit. Most of the person-environment (P-E) fit models focus on the relation between the employee's needs, wishes, goals on the one side and the benefits, conditions, and supplies a job is offering on the other side. A few P-E fit models characterize the relation between employees' abilities, experience, skills and job demands or workload. More sophisticated P-E fit models treat congruence as a dynamic, developing, and interactive process $[9,10,11]$. In conclusion, different types of P-E fit refer to various aspects of work environment e.g., person-group fit, personsupervisor fit, or person-organization fit as well as demands-abilities fit, so P-E fit can be described as a

multidimensional construct. The observed outcomes in these models are usually job satisfaction $[7,8]$ and employee stress along with health measures like burnout [12].

Person-Environment fit is usually operationalized by calculating a fit index, subtracting an individual score from the environment score. There are at least 13 different ways for computing fit indices in P-E fit models [13], each resulting from different variables and components. To name an example, a fit index is often calculated by squaring the difference mentioned above. Thus, P-E fit score indicates the level of fit - disregarding if the environment score was higher than the individual score or vice versa. This needs to be noted critically, as a deficit could lead to a different attitude as an outcome then the same amount of an oversupply. It becomes evident that by calculating a fit index some information can be discarded, which could lead to different complications in the research process.

\section{Gender-Role Orientation}

In the present study, two P-E fit scores are calculated based on the two dimensions of the gender role orientation. Gender-role orientation or gender identity describes the individual self-perception in relation to femininity and masculinity. It reflects how strongly an individual identifies with gender stereotypes and gender roles. The psychosocial aspects culturally associated with feminity and masculinity refer to the bi-polar constructs communion and agency $[14,15]$. Communion focuses on relationship-oriented characteristics such as participation, community, focus on others, forming connections, affirmation of feelings, and is stereotypically related to feminity. Agency follows principles like individualism, focus on self, forming separations, mastery, self-assertion, discipline, 
suppression of feelings, and can be described as task orientation, which refers to masculinity. Other frequently used terms are expressivity (for feminity) and instrumentality (for masculinity) [16], in this article the terms feminity and masculinity are applied consistently. Two prevalent questionnaires, Bem Sex Role Inventory (BSRI) [17] and Personal Attributes Questionnaire (PAQ) or Extended Personal Attributes Questionnaire (EPAQ) [18], are used for measurement. Based on these instruments Gender Role Orientation Scale GTS + containing socially desired adjectives was developed in German [19].

Most studies reveal best mental health [20, 21], highest self-esteem scores [18, 22, 23], highest levels of social competence [24] and better adjustment [25] for individuals with both high feminity, and high masculinity. In this context the term androgyny is applied for balanced and high individual levels of feminity and masculinity.

Among subjects with one-sided gender-role orientation, study results show higher health and well-being scores for individuals with high levels of masculinity and low feminity compared to individuals with high feminity and low masculinity. Additionally, masculinity shows higher effects on health measures than feminity and stronger positive relationship with self-esteem and adjustment $[18,22,24,25,26]$.

Previous scientific debate gives various explanations in this matter. Among other reasons, in general masculine characteristics lead to a more positive self-evaluation and higher self-esteem. As Cook describes it "masculinity has a more powerful impact on how positively you see yourself" (p. 477) [27]. Additionally, a positive self-image is possibly overrated in health research, while feminine dimensions such as ability of emotional self-reflection and emotional expressiveness are ignored in their value for psychological health [28]. Thus, perceived and expressed negative feelings in health questionnaires are possibly connected to less health, and suppressed emotions behind an optimistic attitude would result in higher psychological health scores. Nonetheless, unprocessed mental stress could lead to psychosomatic symptoms and unhealthy stress coping behaviors. This interpretation of relations between masculinity and mental health is called masculine supremacy effect [27] or a "masculine bias" [29].

Another model explaining the interdependency of feminity and masculinity is introduced by Helgeson [30, 31, 32]. The model explains health problems arising in individuals with a high score in one of the dimensions and a low score in the other. In such cases, the model refers to the terms unmitigated communion and unmitigated agency [14]. Unmitigated agency (focus on oneself and exclusion of others) would lead to physiological reactivity and should manifest in biological measures [33]. Unmitigated communion (focus on others and neglect of oneself) would enforce psychological distress, which should become evident in subjective health ratings [34]. This is especially interesting regarding our study focusing effects on subjective and biological stress measures.

\section{Burnout}

Besides other theories, burnout is described as a two-dimensional construct in the Job Demands-Resources (JD-R) model $[35,36,37]$. The two dimensions are exhaustion with physical fatigue symptoms, and cynicism, which leads to cynical and negative attitudes towards work. A common instrument measuring both dimensions is Oldenburg Burnout Inventory (OLBI) [38].

Job Demands-Resources assumes that personality dimensions and social processes at work are operating as job resources and demands. According to the JD-R model, job demands mostly affect employees' burnout while job resources mainly have effects on work engagement $[39,40]$.

Some specific variables related to burnout were identified - among those low support, high job demands and high workload, low autonomy or job control, low reward, and job insecurity $[42,43]$. Another job demand related to 
burnout is high role conflict $[44,45]$. Role conflicts appear in job positions with contrary and conflicting work requirements, conflicting goals, and behaviors.

\section{Work Engagement}

In JD-R theory work engagement is described with three dimensions. Two burnout-contrary dimensions are vigor and dedication. Vigor is described by a high energy level and readiness to invest in work even in challenging situations. Dedication refers to meaningfulness seen in work, as well as perceived enthusiasm and inspiration. The third work engagement dimension is absorption, meaning a state of high concentration and immersion in work [46]. One of the most popular work engagement questionnaires is Utrecht Work Engagement Scale (UWES) [47], also published in a short version [48].

Research reveals positive and negative impacts of work engagement. Highly engaged employees report positive emotional states connected to their work, and proactively change their work environment to create job resources. They show better performance, have better health, less accidents, and their clients report a higher customer satisfaction $[39,40,49]$.

Nevertheless, diverse studies proved that individuals with high work engagement tend to have more overtime-work, which can lead to health strains. In fact, studies reveal a higher work-to-family-conflict for highly engaged employees as well as a raised risk of burnout. In short, there seem to be special conditions on a personal and on the organization level, where work engagement may lead to a negative development $[49,50]$.

\section{Steroid levels in hair as stress biomarkers}

Another way to determine individuals' stress reaction is the usage of biological measurements. Assessment of steroid levels in bodily fluids secreted by the activity of the hypothalamus-pituitary-adrenal neuroendocrine axis during the physiological stress response plays an essential role. While short-term steroid measurements extracted from blood, saliva, urine, or feces are strongly influenced by different factors like nutrition, exercise, nicotine and alcohol consumption, acute stress and circadian rhythm, these also do not have essential harmful effects on health. Human hair has been used for long-term toxicological analyses since the development of applicable methods in the 1980s, due to the known hair's ability to store substances temporarily present in blood. As human hair grows 1 $\mathrm{cm} /$ month (0.39 in) on average [51] hair analysis gives - depending on hair length -information about substance exposure during last months or years. The most common techniques in substance detection are immunochemical techniques, Gas Chromatography-Mass Spectrometry (GC-MS), and Liquid Chromatography-Mass Spectrometry (LC-MS) [52]. The ongoing further development of these methods also enabled detection of steroids like cortisone, estradiol, testosterone, dehydroepiandrosterone (DHEA), progesterone and others in human and animal hair samples $[53,54,55,56,57]$.

Previous research could prove cortisol levels in hair provide a valid and reliable biomarker of the crucial long-term stress explosion $[58,59]$. However, apart from cortisol, study results do not present a consistent picture about correlations between physical, mental, and subjective stress and raised levels of other steroids yet.

\section{Effects of P-E Fit in Feminity and Masculinity}

Studies regarding gender congruence between individual and work environment focus on the social role differences between men and women based on their biological sex. Consequently, in this research gender-congruency between the individual and supervisor or individual and team refers to men and women working in male or female-dominated working environments, none of them indicating differences in feminity or masculinity. Tough, as higher expressivity 
scores could be proved for women and higher instrumentality levels for men $[32,60,19]$, similar results can be expected for individuals with high P-E fit scores in feminity and masculinity.

Previous research verified that women in male-dominated industries had more stress and poorer mental health scores then male employees in the same job-settings [61]. Other studies showed that subjective stress levels were higher for women in male-dominated working environments $[62,60]$ as well as elevated sick leave levels among women in extremely male-dominated occupations [63]. A higher sickness absence was also found among men in female-dominated work settings $[60,63]$. However, a meta-analysis of 183 studies showed that gender differences do not occur in occupations dominated by the same gender [4].

In conformity with P-E fit theories, a low person-environment fit can lead to an increased adjustment effort resulting in higher levels of perceived stress. Therefore, the higher a P-E fit score (meaning lower fit), the more stress, burnout or other health complaints can be expected.

P-E fit research focuses on subjective stress measures as outcomes and provides no studies on hair steroid levels in this context. Nevertheless, above explanations lead to the conclusion that, a higher P-E fit related to gender-roleorientation leads to higher levels of subjective stress, and this should manifest in physiological stress measures. As hair cortisol is a proven biomarker for long term stress levels [58, 59], higher P-E fit scores in feminity and masculinity (indicating a lower fit) should be related with higher hair cortisol levels. The interdependency with other hair steroids needs to be specified, as previous research provides no consistent picture.

P-E fit related to gender-role-orientation has not been explored regarding work engagement. A general personorganization value congruence and work engagement were proved to be positively correlated with each other [64]. Person-organization value congruence could be proved as a moderator between engagement and burnout. For nonmanagerial employees, it enhanced the negative relationship between job engagement and burnout. Thus, low levels of person-organization value congruence appear along with lower engagement and higher burnout scores. On the other hand, for employees in managerial positions the opposite was observed. Managers with a high personorganization value congruence report more engagement and - enhanced by person-organization value congruence higher burnout levels [50].

\section{Present study goals}

The observations described above lead to the following hypotheses as shown in Fig. 1. The first hypothesis (H1), which claims that P-E fit feminity and masculinity have positive effects on burnout and psychosomatic complaints after considering age and work characteristics. The second hypothesis $(\mathrm{H} 2)$ declares that P-E fit feminity and masculinity have positive effects on steroid measures in hair after considering age and work characteristics. The third hypothesis (H3) states that P-E fit feminity and masculinity shows an effect on work engagement and enhances the negative relation between work engagement and burnout as a moderator variable in a sample of nonmanagerial employees.

All hypotheses are proved in hierarchical linear regression models to analyze if P-E fit in feminity and masculinity still add significant variance explanation after considering age and work characteristics. To explain more variance of the outcomes, mediator and moderator effects are examined.

In the study, two P-E fit scores are calculated by subtracting individual femininity and masculinity from related characteristics of work environment in order to analyze their effects on target variables. This is reasonable regarding 
the mere gender group recording in stress research because in this way a gender-related diversity within the gender groups can be considered more specifically.

This also might offer an alternative to stress and burnout cause research, since gender groups are not used as predictors but gender-role-related characteristics of individuals and the work environment. A distinction of the stress and burnout values among gender groups only allows a descriptive comparison. By identifying effects of P-E fit in femininity and masculinity, appropriate and more specific approaches in stress and burnout prevention and promotion of work engagement can be developed.

Another special feature of the study is that reference is made to subjective stress values (e.g. burnout) as well as hair steroids as stress biomarkers.

\section{Methods}

\section{Study Design, Statistical Methods, and Sample Size}

To prove the hypotheses a cross-sectional study was implemented and has been described in detail in an earlier publication [65], a brief method outline is given in this article. The collected data (see Supplementary, Additional file 2) was analyzed using descriptive statistical methods as well as hierarchical linear regression models, including moderator and mediator analysis. In the survey persons age and occupational demands were included in the hierarchical linear regression models to prove whether P-E fit feminity and masculinity still add considerable variance explanation to the outcomes.

A sample size of 55 subjects was calculated for simple linear regression models $(a=0.05$, power $=0.80)$. For multiple linear regression models including more predictors, a bigger sample size is required, up to 92 subjects for multiple linear regression models including five predictors, and a minimum of 85 subjects for Pearson's bivariate correlation.

\section{Measures}

\section{Predictors}

P-E fit feminity and masculinity were investigated as predictors in all three hypotheses. GTS + scale [19] was used for measuring feminine and masculine gender role orientation. First, the participants were asked to describe themselves answering the questionnaire. In a second step, the subjects characterized their work environment including colleagues and supervisors using the same scale. To operationalize P-E fit score a difference score was built, subtracting the individual rating from the subjective rating for work environment. In a next step, the values were transformed by squaring and logarithmizing to meet the requirements for linear regression. This way, the two predictor variables P-E fit in feminity and P-E fit in masculinity were calculated. Both variables do not differentiate between cases with higher scores in individual or environmental feminity and masculinity. The predictors rather quantify a general fit. This way, high values in both P-E fit scores represent a bigger difference between the individual and environment feminity or masculinity. Accordingly, low values indicate less difference and a better fit.

Considered job demands include 18 variables: Activity scope, task completeness, development chances, workplace ergonomics, working time flexibility, work interruptions, work material supply, information supply, versatility of cognitive tasks, role clarity, physical exhaustion, work-qualification equivalency, quantitative work demands, role 
conflicts, work organization, task variety, work-life balance, and work environment strains. All job demands were quantified by the newly validated DearEmployee-Survey questionnaire [66].

\section{Outcomes}

In the study burnout and number psychosomatic complaints ( $\mathrm{H} 1)$, hair steroids including cortisol, cortisone, dehydroepiandrosterone [DHEA], testosterone as well as progesterone $(\mathrm{H} 2)$, and work engagement $(\mathrm{H} 3)$ are analyzed as outcomes.

To identify burnout, psychosomatic complaints, and work engagement the DearEmployee-Survey [Wiedemann et al] was used in the study. To measure steroids, hair samples were taken and analyzed by Liquid ChromatographyMass Spectrometry (LC-MC/MS) $[52,59]$ in a specialized laboratory.

\section{Participants}

A total of 171 of 411 employees answered the online query (42\%). Due to lacking statistical relevance, 19 male participants (two of them provided hair samples) and 6 participants not identifying their gender were excluded from the analysis ( $15 \%$ of all subjects taking part in the query).

The sample involves 146 women who answered a self-assessment questionnaire, 58 of them (40\%) submitted hair samples for steroid detection. As the participation was voluntary, all subjects selected themselves into the sample. No agreements were made with participants, no payments were made to them. All female participants answering the online query or submitting hair samples were considered part of the study, no restrictions leading to exclusionexcept biological sex-were made. The participants were 22 to 66 years old $(M=40.48, S D=10.38, R=44)$, six female participants did not mention their year of birth (4\%). Nearly all subjects-136 out of 146-had a permanent working contract in the company (93\%), three participating employees had a fixed-term working contract ( $2 \%)$, three other participants had a working contract allowing a maximum wage of 400 Euros (2\%), one person was working on probation $(<1 \%)$, two of the query participants were student assistants (1\%). Above all female subjects 8 participants $(6 \%)$ confirmed having a side income.

The sample of 58 female participants delivering hair samples is described in the following. In this group two subjects age was "less than 24 years" (3\%), 12 subjects were "25-34 years" old (21\%), 21 subjects were "35-44 years" old (36\%), the age of 15 subjects was "45-54 years" (26\%), and eight subjects were "55-64 years" old (14\%). The marital status of 29 participants was "single" (50\%), 21 subjects were "married" (36\%), three subjects stated to be „married, but living separated“ (5\%), and five participants indicated themselves as „divorced“ (9\%).

\section{Results}

The study focuses on the effects of P-E fit in feminity and P-E fit in masculinity on burnout, psychosomatic complaints, hair steroids, and work engagement. Descriptive statistics are stated in Supplementary Table 1, Additional File 1 (predictor variables, job demands and control variable age) and Table 2, Additional File 1 (Health Strains, hair steroids, and job engagement).

An overview of Pearson's bivariate correlations between predictors, burnout, psychosomatic complaints, hair steroids, work engagement, and age as a control variable is given in Table 1. P-E fit in feminity correlates significantly with burnout as well as age and has a negative correlation with work engagement. P-E fit in masculinity correlates significantly with cortisol and age (negative interrelation). Variables DHEA, testosterone and progesterone have no significant relations with any of the predictor variables. 
Table 1

Pearson's correlations of P-E fit in feminity and masculinity, health strains, hair steroids and age.

\begin{tabular}{|c|c|c|c|c|c|c|c|c|c|c|c|}
\hline Variable & 1 & 2 & 3 & 4 & 5 & 6 & 7 & 8 & 9 & 10 & 11 \\
\hline $1 \mathrm{FFem}^{\mathrm{a}}$ & 1 & & & & & & & & & & \\
\hline $2 \mathrm{FMasc}^{\mathrm{b}}$ & .01 & 1 & & & & & & & & & \\
\hline 3 Burnout & $.31^{\star \star \star}$ & .02 & 1 & & & & & & & & \\
\hline $\begin{array}{l}4 \\
\text { Complaints }\end{array}$ & .12 & -.05 & $.44^{\star \star \star}$ & 1 & & & & & & & \\
\hline 5 Cortisol & .28 & $.32^{\star}$ & $<.01$ & -.08 & 1 & & & & & & \\
\hline 6 Cortisone & .16 & .20 & .12 & .24 & $.73^{\star \star \star}$ & 1 & & & & & \\
\hline 7 DHEA & -.02 & -.08 & -.02 & -.05 & -.07 & $-.29 *$ & 1 & & & & \\
\hline $\begin{array}{l}8 \\
\text { Testosterone }\end{array}$ & -.18 & -.12 & -.40 & .31 & .69 & .29 & .63 & 1 & & & \\
\hline $\begin{array}{l}9 \\
\text { Progesterone }\end{array}$ & -.23 & .03 & -.04 & -.13 & -.08 & -.23 & .26 & .36 & 1 & & \\
\hline $\begin{array}{l}10 \\
\text { Engagement }\end{array}$ & $-.25^{\star \star}$ & -.05 & $-.44^{\star \star \star}$ & $-.37 * \star$ & .03 & .12 & -.23 & -.15 & -.24 & 1 & \\
\hline 11 Age & 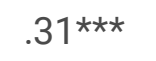 & $-.23^{\star \star}$ & $.32^{\star \star \star}$ & .18 & .12 & .15 & -.07 & .09 & -.25 & -.01 & 1 \\
\hline
\end{tabular}

Table 3 in Supplementary Additional File 1 shows correlations between P-E fit in feminity and masculinity, burnout, complaints, work engagement, age, and job demands. P-E fit in feminity shows poor correlations with development chances, workplace ergonomics, working time flexibility, information supply and quantitative work demands. No significant correlations could be found between any occupational demand variables and P-E fit in masculinity. Intercorrelations between job demand variables are summarized in Supplementary Additional File 1, Table 4.

Hierarchical linear regression models (see also Supplementary Additional file 1, Table 5 and Table 6) including moderator and mediator analyses were inspected to improve the variance explanation of P-E fit in feminity and masculinity for the outcome variables.

The first hypotheses $(\mathrm{H} 1)$ claims predictor effects on subjective health strain measures burnout and complaints, age and work demand variables were included in the analysis. A strong variance explanation could be verified for burnout in a hierarchical multiple regression model - Fig. 2 provides an overview. After including age, job demand variables role conflicts and work organization in the model, P-E fit in feminity still added significant variance explanation on burnout.

P-E fit in masculinity could not be proved as a predictor for burnout. Regarding both predictors, no variance explanation on the number of psychosomatic complaints could be proved.

The second hypothesis $(\mathrm{H} 2)$ claims predictor effects on hair steroids including cortisol, cortisone, DHEA, testosterone and progesterone. A hierarchical linear regression model with two steps could be verified as shown in Fig. 3 explaining the variance in hair cortisol. After adding quantitative work demands to the model in the first step, P-E fit 
in masculinity gender role orientation still added significant variance explanation on hair cortisol. No mediator or moderator effects could be proved in this model. No effects could be verified on other steroids. Age and P-E fit in feminity explained no significant variance on any of the hair steroid measures.

The third hypothesis $(\mathrm{H} 3)$ states predictors' variance explanation on work engagement as well as predictors' moderator effects on the relation between work engagement and burnout.

We could attest poor variance explanation of work engagement by P-E fit in feminity $\left(\beta=-.29, R^{2}=.09, F(1,136)=\right.$ $12.85, p<.001,95 \% \mathrm{Cl}[-1.50,-.28])$, multiple regression models involving additional predictors did not show statistical relevance. Effects of P-E fit in masculinity on work engagement could not be verified. The analysis also did not approve any moderator effects.

\section{Discussion}

The first hypothesis, claiming that P-E fit in feminity and masculinity have effects on subjective health strain measures, was only proved for P-E fit in feminity having a significant positive effect on burnout. Results showed that P-E fit in feminity still added significant variance explanation on burnout after considering age, role conflicts, and work organization. However, the second hypothesis, declaring that P-E fit in feminity and masculinity have positive effects on hair steroids as biological stress markers, could only be verified for P-E fit in masculinity having a significant positive effect on hair cortisol. P-E fit in masculinity added significant variance explanation on hair cortisol after including quantitative work demands in the model. Study results partly supported the third hypothesis claiming that P-E fit in feminity predicts work engagement. However, no moderator effects could be verified. Similarly, no effects of P-E fit in masculinity could be proved on work engagement.

As P-E fit in feminity was proved adding significant variance explanation to burnout, our research could provide an advanced and more specified explanation for usually identified higher burnout levels in woman $[4,5]$. For, if female employees have higher feminity scores than their male colleagues [32,60,62], in a work environment with perceived low feminity, this could result in elevated P-E fit in feminity (a bigger difference in individual and environment score) in the group of women. Thus P-E fit in feminity - and not female gender - possibly manifests in higher burnout levels in women. Further, our study might show a new way to explore reasons for burnout in general - e.g., also for male employees with high feminity levels in work environments with low feminity.

Our study results cannot directly explain commonly reported higher cortisol levels in men compared to women [67] as P-E fit in masculinity showed positive effects on cortisol levels. Male individuals usually have higher masculinity levels compared to women $[60,62]$. In a work environment with perceived high masculinity this would lead to lower P-E fit levels (less difference in masculinity). As the study involved a female sample, a possible conclusion could be drawn that lower cortisol levels are usually reported for women compared to men as women might tendentially not perceive a big difference in their individual and work environment masculinity. Thus, it would possibly rather be more reasonable to raise female characteristics in company and team culture then to change masculine characteristics to prevent burnout in women.

Apart from that, the indicated effects of job characteristics on burnout and hair steroids as stress biomarkers are not surprising. The results expose already known burnout correlated job demands, such as role conflicts (see Fig. 2) and quantitative demands (see Fig. 3) as frequently shown by burnout research [42, 43, 68]. As in previous research [58], we could prove effects on cortisol as a biomarker for stress, but not on other steroids. 
Our study confirmed P-E fit in feminity explaining significant variance in work engagement. This corresponds to other study results involving general person-organization value congruence [64]. Employees' P-E fit in feminity might play a special role in connection with work engagement, as P-E fit in masculinity did not show a similar effect.

\section{Study strengths and limitations}

It must be considered that only 58 subjects provided hair samples in the study. Sufficient power of $80 \%$ could not be always ensured in the statistical analyses regarding hair steroid levels, since Pearson's correlation and linear regression models with more than one predictor require a bigger sample size. This way, some existing correlations and regression effects - especially those regarding effects on hair steroids $(\mathrm{H} 2)$ - may not be discovered.

As the moderator effects of P-E fit in feminity and masculinity on work engagement were not supported, we need to consider that previous studies show correspondent moderator effects for general person-organization value congruence [50]. This may not be applicable for the specific P-E fit measures used in our study.

Another critical point is the calculation of P-E fit in feminity and masculinity, where squaring and logarithmizing were involved. This transformation was necessary to meet the requirements for linear regression. However, after these steps no difference can be made in cases where one's own gender role orientation level is rated higher than gender role orientation of the job environment or vice versa. This could be crucial to investigate the interdependencies of the variables, though.

Further, the cross-sectional observational study design only allows conclusions about interrelations of the variables, no causal effects (e.g., as shown in the regression models) can be verified.

For result generalization, it is particularly important that the chosen sample were women employees in a medical services company. As psychological, social, and biological aspects of biological sex and gender are crucial in this research as well as specific job characteristics and company culture, a broad generalization of the study results is not appropriate.

To emphasize the advantages of the study, not only relations between individual feminity, masculinity and mental health were analyzed, as it is the case in previous research. Gender-role associated work environment and individual characteristics were both linked to each other in calculating P-E fit in feminity and masculinity, and analyzed as a predictor for stress, burnout, and work engagement.

Additionally, the study might improve occupational stress research in relation to gender congruence studies, since previous studies relate to biological sex and social role of male and female individuals as stress predictors, not differentiating within gender groups. Whereas, our study focused on effects of P-E fit in gender-role orientation, which could show a more sophisticated way to identify actual individual and work environment characteristics predicting stress and burnout.

Research of sex or gender congruence in occupational environment as predictors for stress and health strains only enables a descriptive comparison. The only practical implication, which can be derived from gender congruence research is a broader inclusion and diversity in different business areas. While this is a reasonable step, this will probably not be the final solution as relevant differentiation is needed within gender groups as well as in the description of company culture. To put it simply, more specific tools are needed to deal with the relevant present-day challenges in occupational stress prevention.

\section{Future Research}


To gain a more comprehensive picture, in the future it might be reasonable to investigate the effects of P-E fit in feminity and masculinity on hair steroids with bigger samples. Especially cortisol should be focused on, but also interrelations between P-E fit, burnout, and other hair steroids could be specified in further studies.

Apart from the sample size, sample characteristics - such as biological sex, gender, age - should also be adapted to bigger target populations to enable a broader result generalization. It might be especially interesting, if male subjects with a high P-E fit in feminity show similar effects as female subjects.

Further research could also reveal, if the discussed effects can be differentiated depending on if feminity or masculinity are rated higher for individual or job environment, thus giving fit scores a more specific differentiation. Longitudinal observations should be undertaken to further investigate long-term effects.

In summary, the study shows effects of P-E fit in feminity on burnout and work engagement as well as effects of P-E fit in masculinity on biological stress markers. Further research with larger and more diverse samples as well as longitudinal studies are needed to explore the advantages and the limits in this approach. P-E fit in feminity and P-E fit in feminity could represent improved methods in gender-related stress research. Both scores might be considered as relevant predictors, which could improve stress and burnout prevention and promote work engagement as specific interventions could be derived.

\section{Conclusions}

The presented study leads to the conclusions that on one hand P-E fit score in feminity possibly represents a considerable predictor variable for burnout and work engagement. On the other hand, P-E fit scores in masculinity could be considered an important predictor variable for cortisol measures in hair as biological stress markers.

Using P-E fit feminity and masculinity instead of gender congruence in research has several benefits. Feminity as a characteristic for focusing connections to others, and masculinity as a dimension for focusing on oneself and on the individual goals may be viewed as attributes of company culture, as individual and group competencies.

One practical implication for occupational health medicine and psychology as well as human resources development is to consider a close intercommunion between the two areas. An example could be taken from the diversity management approach in which economic decisions can be made considering health aspects and vice versa $[69,70]$. Further practical implications can be derived for working culture, team composition and team development for a healthy work environment. Improved and specific approaches to lower occupational stress and burnout levels could contribute to the prevention of psychological illnesses, which are an ongoing public health issue in the last decades.

Not to forget, it might be beneficial to raise feminity characteristics in work environment and company culture to raise work engagement. Accordingly, specific recommendations could be developed to increase employee work engagement, which relates positively with lower burnout levels and better performance. In addition to this, companies also benefit from this knowledge by improving their work environment, thus positioning themselves as a desirable employer to address the shortage of skilled employees.

\section{Declarations}

\section{Authors' contributions}

Page 12/19 
EW made substantial contributions to the conception and design of the study, acquisition, analysis, and interpretation of data. The first draft of the manuscript was written by EW. JS made substantial contributions to the conception and design of the study and revised the manuscript substantively. AF revised the manuscript substantively.

\section{Acknowledgements}

We want to thank all employees of the medical services company for participating in this study and company's management and works council for the good cooperation.

We would also like to express our thank to DearEmployee $\mathrm{GmbH}$, Bismarckstr. 10-12, 10625 Berlin who provided the questionnaire used in the survey and organized the query.

We would like to acknowledge the support of Technische Universität Dresden, Professur Biopsychologie, 01062 Dresden laboratory for analyzing the hair samples.

\section{Consent for publication}

Not applicable

\section{Ethics approval and consent to participate}

Ethics committee: Charité, 10117 Berlin, Ethikkommission, Ethikausschuss 4 am Campus Benjamin Franklin. Statement on ethics approval and consent: Reference number: EA4/054/17, $3^{\text {rd }}$ May 2017 and $21^{\text {st }}$ June 2017. Copies are available to the Editor on request.

\section{Availability of data and materials}

Data generated and analyzed during this study are included in this published article and its supplementary information, Additional file 2.

\section{Competing interests}

The authors declare that they have no competing interests.

\section{Funding}

The study was sponsored by Institut für Arbeitsmedizin der Charité - Universitätsmedizin Berlin, Augustenburger Platz 1, 13353 Berlin, Germany.

\section{References}

1. Burnout in the workplace: A review of data and policy responses in the EU. Luxembourg: Publications Office of the European Union; 2018.

2. European Migration Network. Determining labour shortages and the need for labour migration from third countries in the EU. 2015. https://ec.europa.eu/home-affairs/sites/homeaffairs/files/what-wedo/networks/european_migration_network/reports/docs/emnstudies/emn_labour_shortages_synthesis_final.pdf. Accessed 09 Dec 2020. 
3. European Research Council. Sex and Gender Dimension in Frontier Research. 2020.

https://erc.europa.eu/event/sex-and-gender-dimension-frontier-research. Accessed 11 Dec 2020.

4. Purvanova RK, Muros JP. Gender differences in burnout. J Vocat Behav. 2010; doi:10.1016/j.jvb.2010.04.006.

5. Membrive-Jiménez MJ, Pradas-Hernández L, Suleiman-Martos N, Vargas-Román K, Cañadas-De la Fuente GA, Gomez-Urquiza JL, et al. Burnout in Nursing Managers: A Systematic Review and Meta-Analysis of Related Factors, Levels and Prevalence. Int. J. Environ. Res. Public Health. 2020; doi:10.3390/ijerph17113983.

6. Holland JL. Making vocational choices: a theory of vocational personalities and work environments. Odessa: Psychological Assessment Resources; 1997.

7. Dawis RV, England GW, Lofquist LH. A theory of work adjustment. Minnesota Studies in Vocational Rehabilitation No. 15. Minneapolis: University of Minnesota Press; 1964.

8. Dawis RV, Lofquist LH. A psychological theory of work adjustment. Minneapolis: University of Minnesota Press; 1984.

9. Tinsley HEA. The Congruence Myth: An Analysis of the Efficacy of the Person-Environment Fit Model. J Vocat Behav. 2000; doi:10.1006/jvbe.1999.1727.

10. Kristof-Brown AL, Zimmerman RD, Johnson EC. Consequences of individual's fit at work: A meta-analysis of person-job, person-organization, person-group, and person-supervisor fit. Pers Psychol. 2005; doi:10.1111/j.1744-6570.2005.00672.x.

11. Van Vianen AEM. Person-environment fit: a review of its basic tenets. Annu. Rev. Organ. Psychol. Organ. Behav. 2018; doi:10.1146/annurev-orgpsych-032117-104702.

12. French JRP, Caplan RD, Harrison RV. The Mechanisms of Job Stress and Strain. London: Wiley; 1982.

13. Camp CC, Chartrand JM. A comparison and evaluation of interest congruence indices. J Vocat Behav. 1992; doi:10.1016/0001-8791(92)90018-u.

14. Bakan D. The duality of human existence: An essay on psychology and religion. Chicago: Rand McNally; 1966.

15. Sczesny S, Nater C, Eagly AH. Agency and communion: Their implications for gender stereotypes and gender identities. In: Abele AE, Wojciszke B, editors. Agency and Communion in Social Psychology. Current Issues in Social Psychology. 2019. doi:10.4324/9780203703663-9.

16. Parsons T, Bales RF. Family, Socialization and Interaction Process. Glencoe: The Free Press; 1955.

17. Bem SL. The measurement of psychological androgyny. J Consult Clin Psychol. 1974; doi:10.1037/h0036215.

18. Spence JT, Helmreich R, Stapp J. Ratings of self and peers on sex role attributes and their relation to self esteem and conceptions of masculinity and femininity. J Pers Soc Psychol 1975; 32: 29-39.

19. Altstötter-Gleich C. Expressivität, Instrumentalität und psychische Gesundheit. J. Individ. Differ. 2004; doi:10.1024/0170-1789.25.3.123.

20. Eichinger J, Heifetz LJ, Ingraham C. Situational shifts in sex role orientation: Correlates of work satisfaction and burnout among women in special education. Sex Roles. 1991; doi:10.1007/BF00292532.

21. Hawkins CA Hawkins RC. Relationship of social service managers' instrumental and expressive traits to job burnout. International Journal of Business, Humanities, and Technology 2016; 6 Suppl 1: 24-30.

22. Bem SL. On the utility of alternative procedures for assessing psychological androgyny. J Consult Clin Psychol. 1977; doi:10.1037/0022-006X.45.2.196.

23. Luo S, Yun H, Wang Y. Syncretic self-esteem relates to both agency and communion. Curr Psychol. 2020; doi:10.1007/s12144-020-01206-0. 
24. Berzins JI, Welling MA, Wetter RE. A new measure of psychological androgyny based on the Personality Research Form. J Consult Clin Psychol. 1978; doi:10.1037/0022-006X.46.1.126.

25. Della Selva PC, Dusek JB. Sex role orientation and resolution of Ericksonian crises during the late adolescent years. J Pers Soc Psychol. 1984; doi:10.1037/0022-3514.47.1.204.

26. Wojciszke B, Bialobrzeska O. Agency versus Communion as Predictors of Self-esteem: Searching for the Role of Culture and Self-construal. Polish Psychol. Bull. 2014; doi:10.2478/ppb-2014-0057.

27. Cook EP. Psychological Androgyny A Review of the Research. Couns Psychol. 1987; doi:10.1177/0011000087153006.

28. Hyde JS, Grabe S. Meta-analysis in the psychology of women. In: Denmark FL, Paludi MA, editors. Psychology of women: A handbook of issues and theories. Westport: Praeger; 1993. p. 42-73.

29. Alfermann D. Femininität und Maskulinität oder: Haben wir ein maskulines Bias? In: Brähler E, Felder H, editors. Weiblichkeit, Männlichkeit und Gesundheit. Psycholsoziale Medizin und Gesundheitswissenschaften 5. Wiesbaden: Springer Fachmedien; 1999. p. 58-71.

30. Helgeson VS. Relation of agency and communion to well-being: Evidence and potential explanations. Psychol Bull 1994;116 Suppl 3: 412-428.

31. Helgeson VS, Fritz HL. A theory of unmitigated communion. Pers. Soc. Psychol. Rev. 1998; doi:10.1207/s15327957pspr0203_2.

32. Saragovi C, Koestner R, Aube J, Di Dio L. Agency, Communion, and Weil-Being: Extending Helgeson's (1994) Model. J Pers Soc Psychol. 1997; doi:10.1037/0022-3514.73.3.593.

33. Helgeson VS, Orchard TJ, Seltman H, Becker D, Libman I. Psychosocial predictors of diabetes risk factors and complications: An 11-year follow-up. Health Psychol. 2019; https://doi.org/10.1037/hea0000730

34. Jin L, Van Yperen NW, Sanderman R, and Hagedoorn M. Depressive symptoms and unmitigated communion in support providers. Eur. J. Pers. 2010; doi: 10.1002/per.741.

35. Demerouti E, Bakker AB, Nachreiner F, Schaufeli WB. The job demands-resources model of burnout. J Appl Psychol. 2001; doi.org/10.1037/0021-9010.86.3.499.

36. Bakker AB, Demerouti E, Sanz-Vergel Al. Burnout and Work Engagement: The JD-R Approach. Annu. Rev. Organ. Psychol. Organ. Behav. 2014; doi:10.1146/annurev-orgpsych-031413-091235.

37. Bakker AB, Demerouti E. Job demands-resources theory: Taking stock and looking forward. J Occup Health Psychol. 2016; doi:10.1037/ocp0000056.

38. Demerouti E, Bakker AB, Vardakou I, Kantas A. The convergent validity of two burnout instruments: A multitraitmultimethod analysis. Eur J Psychol Assess. 2003; doi:10.1027/1015-5759.19.1.12.

39. Bakker AB, Demerouti E. Towards a model of work engagement. Career Dev. Int. 2008; doi:10.1108/13620430810870476.

40. Bakker AB, Leiter MP, editors. Work engagement: A handbook of essential theory and research. New York: Psychology Press; 2010.

41. Bakker AB, Leiter MP. Work engagement: Introduction. In: Bakker AB, Leiter MP, editors. Work engagement: $A$ handbook of essential theory and research. New York: Psychology Press; 2010. p. 1-9.

42. Schaufeli WB, Buunk BP. Burnout: An overview of 25 years of research and theorizing. In: Schabracq MJ, Winnubst JAM, Cooper CL, editors. The handbook of work and health psychology. 2nd ed. West Sussex: Wiley; 2003. p. 383-429. 
43. Aronsson G, Theorell T, Grape T, Hammarström A, Hogstedt C, Marteinsdottir I, et al. A systematic review including meta-analysis of work environment and burnout symptoms. BMC Public Health. 2017; doi:10.1186/s12889-017-4153-7.

44. Vullinghs JT, De Hoogh AHB, Den Hartog DN, Boon C. Ethical and Passive Leadership and Their Joint Relationships with Burnout via Role Clarity and Role Overload. J. Bus. Ethics. 2018; doi:10.1007/s10551-0184084-y.

45. Frögeli E, Rudman A, Lövgren M, Gustavsson P. Problems with task mastery, social acceptance, and role clarity explain nurses' symptoms of burnout during the first professional years: A longitudinal study. Work. 2019; doi:10.3233/WOR-192892.

46. Schaufeli WB, Salanova M, González-Romá V, Bakker AB. The measurement of engagement and burnout: a two sample confirmatory factor analytic approach. J Happiness Stud. 2002; doi:10.1023/A:1015630930326.

47. Schaufeli WB, Bakker AB. UWES Utrecht Work Engagement Scale Preliminary Manual. Utrecht University: Occupational Health Psychology Unit; 2004.

48. Schaufeli WB, Bakker AB, Salanova M. The Measurement of Work Engagement With a Short Questionnaire: A Cross-National Study. Educ Psychol Meas. 2006; doi:10.1177/0013164405282471.

49. Bakker AB, Albrecht SL, Leiter MP. Key questions regarding work engagement. Eur. J. Work. Organ. Psychol. 2011; doi:10.1080/1359432X.2010.485352.

50. Rabenu E, Shkoler O, Lebron MJ, Tabak F. Heavy-work investment, job engagement, managerial role, personorganization value congruence, and burnout: A moderated-mediation analysis in USA and Israel. Curr Psychol. 2019; doi:10.1007/s12144-019-00423-6.

51. Wennig R. Potential problems with the interpretation of hair analysis results. Forensic Sci. Int. 2000; doi:10.1016/s0379-0738(99)00146-2.

52. Pragst F, Balikova MA. State of the art in hair analysis for detection of drug and alcohol abuse. Clin. Chim. Acta. 2006; doi:10.1016/j.cca.2006.02.019.

53. Yang HZ, Lan J, Meng YJ, Wan XJ, Han DW. A preliminary study of steroid reproductive hormones in human hair. J. Steroid Biochem. Mol. Biol. 1998; doi:10.1016/s0960-0760(98)00120-4.

54. Choi MH, Chung BC. GC-MS determination of steroids related to androgen biosynthesis in human hair with pentafluorophenyldimethylsilyl-trimethylsilyl derivatisation. Analyst, 1999; doi:10.1039/A903912K.

55. Kintz P, Cirimele V, Jeanneau T, Ludes B. Identification of testosterone and testosterone esters in human hair. J Anal Toxicol. 1999; doi:10.1093/jat/23.5.352.

56. Kintz P, Cirimele V, Ludes B. Physiological concentrations of DHEA in human hair. J Anal Toxicol. 1999; doi:10.1093/jat/23.6.424.

57. Perogamvros I, Keevil BG, Ray DW, Trainer PJ. Salivary cortisone is a potential biomarker for serum free cortisol. J. Clin. Endocrinol. Metab. 2010; doi:10.1210/jc.2010-1215.

58. Stalder T, Kirschbaum C. Analysis of cortisol in hair - state of the art and future directions. Brain Behav. Immun. 2012; doi:1016/j.bbi.2012.02.002.

59. Gao W, Kirschbaum C, Grass J, Stalder T. LC-MS based analysis of endogenous steroid hormones in human hair. J. Steroid Biochem. Mol. Biol. 2016; doi:10.1016/j.jsbmb.2015.12.022.

60. Evans $0, \&$ Steptoe A. The contribution of gender-role orientation, work factors and home stressors to psychological well-being and sickness absence in male- and female-dominated occupational groups. Soc. Sci. Med. 2002; doi:10.1016/S0277-9536(01)00044-2. 
61. Gardiner M, Tiggemann M. Gender differences in leadership style, job stress and mental health in male- and female-dominated industries. J Occup Organ Psychol. 1999; doi:10.1348/096317999166699.

62. Hunt K, Emslie C. Men's work, women's work? Occupational sex roles and health. In: Orth-Gomer K, Chesney M, Wenger NK, editors. Women, stress, and heart disease. Mahwah: Lawrence Erlbaum; 1998. p. 87-110.

63. Hensing G, Alexanderson K, Akerlind I, Bjurulf P. Sick-leave due to minor psychiatric morbidity: Role of sex integration. Soc Psychiatry Psychiatr Epidemiol. 1995; doi:10.1007/BF00784433.

64. Li M, Wang Z, You X, Gao J. Value congruence and teachers' work engagement: The mediating role of autonomous and controlled motivation. Pers. Individ. Differ. 2015; doi:10.1016/j.paid.2015.02.021.

65. Wacker E, Schorlemmer J, Fischer A. Arbeitsbezogener Stress und Geschlechtsidentität Ein Studienprotokoll. Submitted.

66. Wiedemann AU, Fodor D, Jakob H, Detel S, Heuse S. Validierung des Dearmployee-Surveys zur Gefährdungsbeurteilung psychischer Belastung. Submitted.

67. Stalder T, Steudte-Schmiedgen S, Alexander N, Klucken T, Vater A, Wichmann S, et al. Stress-related and basic determinants of hair cortisol in humans: a meta-analysis. Psychoneuroendocrinology. 2017; doi:

10.1016/j.psyneuen.2016.12.017.

68. Lee RT, Ashforth BE. A Meta-Analytic Examination of the Correlates of the Three Dimensions of Job Burnout. J Appl Psychol. 1996; doi:10.1037/0021-9010.81.2.123.

69. Jayne MEA, Dipboye RL. Leveraging Diversity to Improve Business Performance Research Findings and Recommendations for Organizations. Human Resource Management. 2004; doi: 10.1002/hrm.20033.

70. Krishnan SG. Gender Diversity in the Workplace and Its Effects on Employees' Performance. Journal of the Social Sciences, 2020;48 Suppl 3:1888-1898.

\section{Figures}

P-E fit in Feminity

\section{P-E fit in Masculinity}

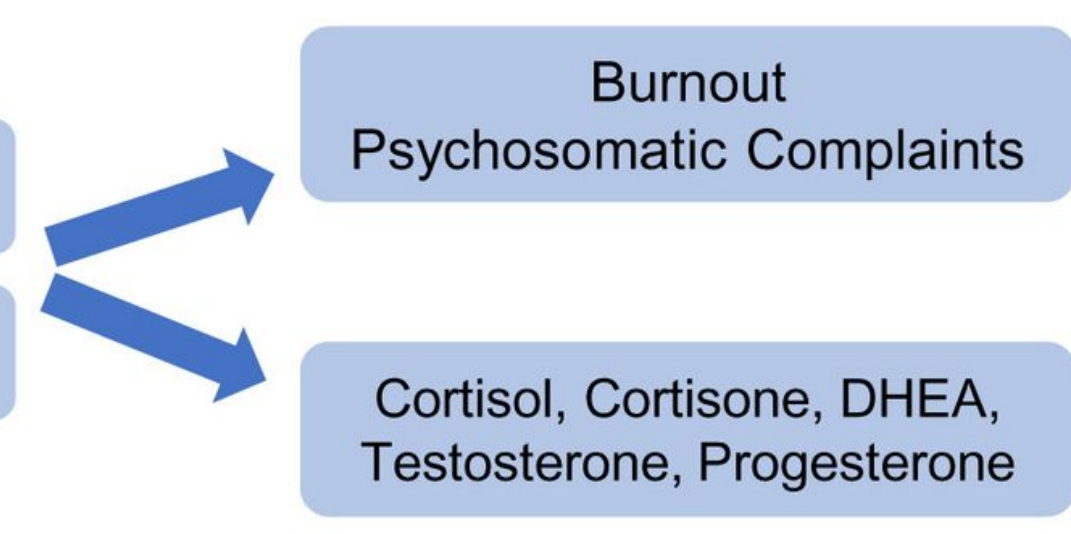

(H1)

$(\mathrm{H} 2)$

(H3)

\section{P-E fit in Feminity}

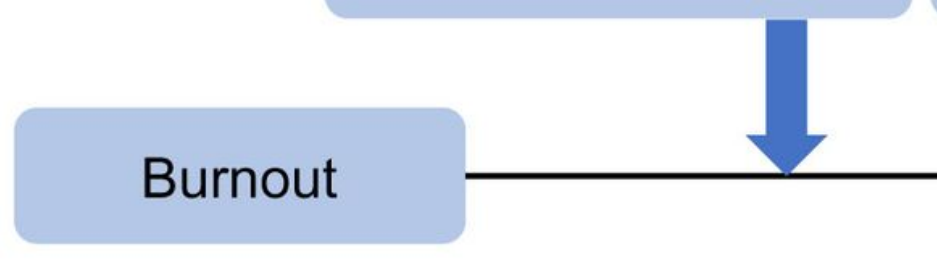

\section{P-E fit in Masculinity}

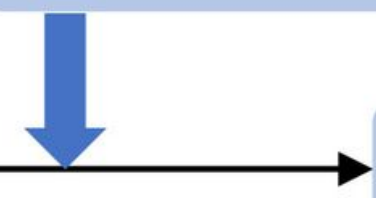

Engagement 
Figure 1

Verified hypotheses on the effects of P-E fit in feminity and masculinity.

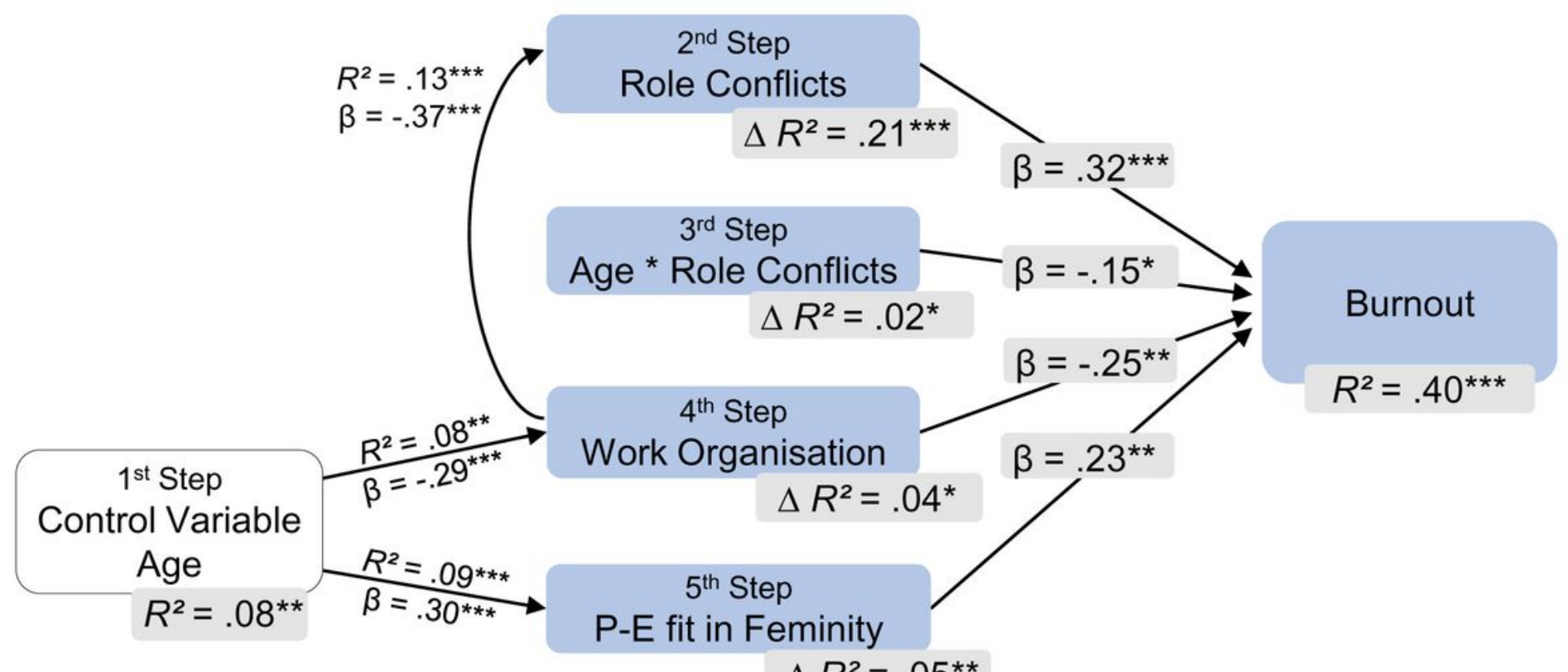

$$
\Delta R^{2}=.05^{\star *}
$$

Figure 2

Effects of P-E fit in feminity in a hierarchical multiple regression model predicting burnout. ${ }^{\star} p<.05, * \star p<.01, \star \star \star ~ p<$ $.001, n=123$.

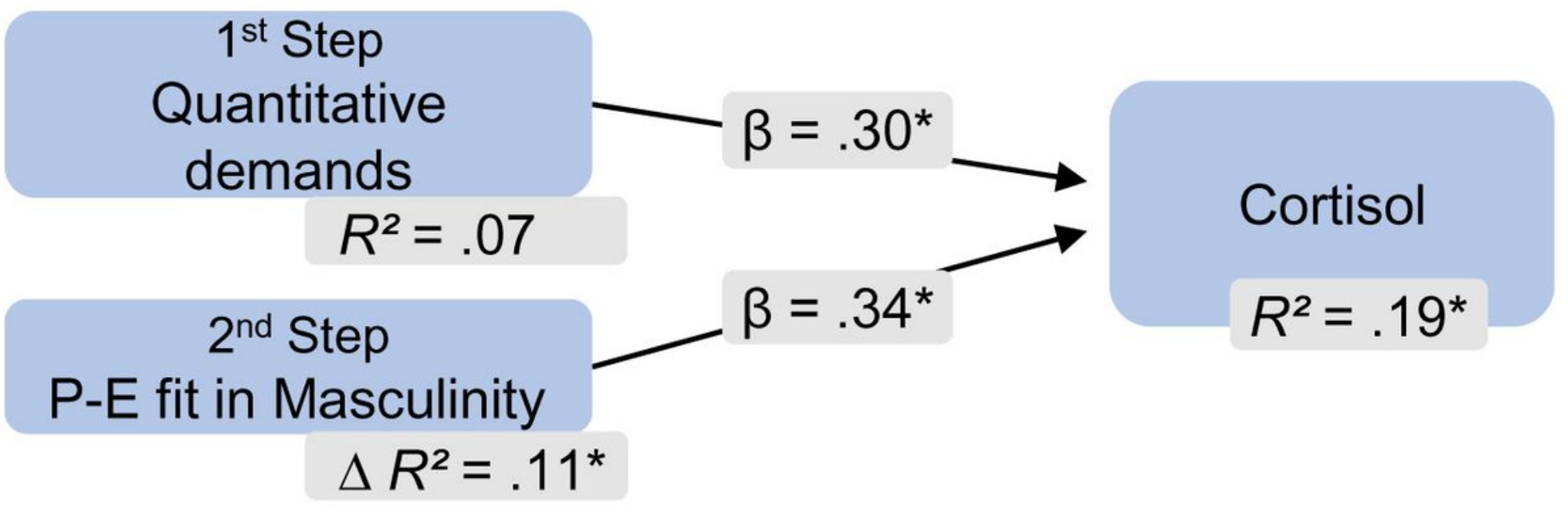

Figure 3

Effects of P-E fit in masculinity in a hierarchical multiple regression model predicting hair. cortisol. * $p<.05,{ }^{\star \star} p<$ $.01, * \star \star p<.001, n=46$.

\section{Supplementary Files}

This is a list of supplementary files associated with this preprint. Click to download. 
- Additionalfile1.pdf

- Additionalfile2dataPEfitStressBurnoutEngagement.xlsx 